\title{
Optical and structural properties of sol gel derived materials embedded in porous anodic alumina
}

\author{
N.V. Gaponenko ${ }^{\text {a,* }}$, I.S. Molchan ${ }^{\text {a }}$, D.A. Tsyrkunov ${ }^{\text {a }, ~ G . K . ~ M a l i a r e v i c h ~}{ }^{\mathrm{a}}$, \\ M. Aegerter ${ }^{\text {b }}$, J. Puetz ${ }^{\text {b }, ~ N . ~ A l-D a h o u d i ~}{ }^{\text {, }}$, J. Misiewicz ${ }^{\text {c }}$, R. Kudrawiec ${ }^{\text {c }}$, \\ V. Lambertini ${ }^{d}$, N. Li Pira ${ }^{d}$, P. Repetto ${ }^{d}$ \\ a Belarusian State University of Informatics and Radioelectronics, P. Browki St.6, 220013 Minsk, Belarus \\ ${ }^{\mathrm{b}}$ Leibniz Institut fuer Neue Materialien, Department of Coating Technology, D 66123, Saarbruecken, Germany \\ ${ }^{\mathrm{c}}$ Institute of Physics, Wroclaw University of Technology, Wybrzeze, Wyspianskiego 27, 50370 Wroclaw, Poland \\ d Centro Ricerche FIAT Optics and Photonics, Strada Torino, 5010043 Orbassano (TO), Italy
}

Available online 7 April 2005

\begin{abstract}
Structures comprising a xerogel, doped with lanthanide ions (erbium, terbium and europium), embedded in porous anodic alumina (PAA) have been fabricated and their optical and electrical characteristics have been studied. Erbium photoluminescence at $1.53 \mu \mathrm{m}$ from titania xerogel/PAA was found to increase with the number of xerogel layers and erbium concentration for the excitation wavelength $532 \mathrm{~nm}$, matching the area of transparency of both titania xerogel and PAA. Visible green and red electroluminescence was observed for terbium and europium doped $\operatorname{In}_{2} \mathrm{O}_{3}$ and $\mathrm{SnO}_{2}$ xerogels embedded in porous anodic alumina. The improvement of the electrical properties of the xerogel/PAA cell is discussed, taking into account the observed ability of conducting $\operatorname{In}_{2} \mathrm{O}_{3}: \operatorname{Sn}$ (ITO) nanoparticles to penetrate into the anodic alumina pores.
\end{abstract}

\footnotetext{
${ }^{*}$ Corresponding author. Tel.: +375 1723988 69; fax: +375 172310914.

Email address: nik@nano.bsuir.edu.by (N.V. Gaponenko).
}

\section{Introduction}

Porous anodic alumina films are of considerable interest due to their cellular structure, with regularly arranged mesoscopic channels of the pores $[1,2]$. Such structures can be used as hosts for sol gel films, which often give new properties to 
these materials. This was shown for the enhanced photoluminescence of erbium, terbium and europium from titania, silica and alumina xerogels embedded in porous anodic alumina of $130 \mu \mathrm{m}$ thickness [3 5].

A promising field of application of lanthanidedoped xerogels is for electroluminescent devices, which are currently the focus of substantial research effort due to potential use in flat panel displays, light emitting diodes, lasers, etc. Most of the work in this area is directed to the synthesis of organic EL materials, and high luminous efficiencies at low operational voltages have been demonstrated [6]. However, organic compounds generally have a number of disadvantages, including poor thermal and mechanical stability, resulting in the occurrence of current voltage instability $[7,8]$.

In this context, it is of interest to use oxidebased lanthanide-doped materials that may be synthesized by simpler methods, such as electrochemical deposition [9] and sol gel synthesis $[10,11]$, which offer improved stability. An additional benefit of study of porous anodic alumina as an electroluminescent cell also arises from the enhanced photoluminescence of lanthanides when embedded therein. Recent reports on the anisotropy of the photonic density of states in porous anodic alumina, with the maximum along the direction of the pore channels $[12,13]$ render this material of interest as a template for electroluminescent structures. A further attractive feature of lanthanide luminescence in xerogels is the low concentration quenching reported for terbium- and europium-doped xerogel/PAA structures $[14,15]$. Recently, titania was considered as a good host for optically active trivalent erbium ions, exhibiting a strong photoluminescence at $1.53 \mu \mathrm{m}$ [16 18 ].

In this work, the possibility of increasing the erbium photoluminescence in xerogel/porous anodic alumina structure is considered, along with prospective application of the structure for electroluminescent devices. Terbium and europium electroluminescence (EL) in $\mathrm{SnO}_{2}$ and $\mathrm{In}_{2} \mathrm{O}_{3}$ xerogels embedded in porous anodic alumina is reported, with the route to assuring electrical contact between the xerogel and the transparent electrode, using a suspension of conducting ITO nanoparticles, is discussed.

\section{Experimental}

Several sol gel derived coatings were used. One group comprises $\mathrm{In}_{2} \mathrm{O}_{3}$ or $\mathrm{SnO}_{2}$ xerogel films fabricated from diluted colloidal solutions of $\mathrm{Sn}(\mathrm{OH})_{2}$ or $\operatorname{In}(\mathrm{OH})_{3}$ that were prepared from tin or indium chloride precursors, accordingly. In order to improve the conductivity of the xerogels, a further group of ITO-xerogel films was fabricated from these solutions using $\mathrm{Sn} / \mathrm{In}$ ratio in xerogel ranging from 4 to $14 \mathrm{~mol} \%$. Titanium dioxide films were prepared from $\mathrm{Ti}\left(\mathrm{OC}_{2} \mathrm{H}_{5}\right)_{4}$ precursor, (see [16] for details). These solutions were mixed with nitrates of lanthanide ions to achieve $3060 \mathrm{wt} \%$ $\mathrm{Er}_{2} \mathrm{O}_{3}, \mathrm{~Tb}_{2} \mathrm{O}_{3}$ or $\mathrm{Eu}_{2} \mathrm{O}_{3}$ in the respective xerogel films.

The last group of coatings, comprising ITO nanoparticles, was fabricated using a suspension of ITO nanoparticles [19].

The films were fabricated by spinning the individual solutions either on wafers of fused silica, or thermally oxidized silicon with $0.1 \mu \mathrm{m}$ thick silicon dioxide or films of PAA. The typical thicknesses of ITO-xerogel film and ITO-film derived from suspension and deposited by spinning on flat surfaces were 0.01 and $0.5 \mu \mathrm{m}$, respectively.

PAA films, 5 and $15 \mu \mathrm{m}$ thick, with a pore diameter of $90 \mathrm{~nm}$, were fabricated by anodizing of an aluminum layer deposited by magnetron sputtering onto silicon substrates; anodizing was carried out at a constant current density of $5.5 \mathrm{~mA} / \mathrm{cm}^{2}$ in $1.2 \mathrm{M} \mathrm{H}_{3} \mathrm{PO}_{4}$. Additionally, selected samples were etched to achieve increased pore diameters. Fig. 1 shows a typical image of such a porous film. To obtain terbium- or europium-related electroluminescence, the sols containing lanthanide ions were deposited onto PAA by spinning at $2700 \mathrm{rpm}$ for $30 \mathrm{~s}$ followed by a thermal treatment. An ITO electrode sputtered onto glass surface was mechanically pressed on the top surface of PAA filled with xerogel (Fig. 2), with the silicon substrate serving as the second electrode.

Room-temperature, $1.53 \mu \mathrm{m}$ infrared emission was studied for titania xerogels containing 30 and $60 \mathrm{wt} \%$ of $\mathrm{Er}_{2} \mathrm{O}_{3}$ fabricated by spinning on a porous anodic alumina. Excitation was performed with an argon laser, operating at 300 or $532 \mathrm{~nm}$. 


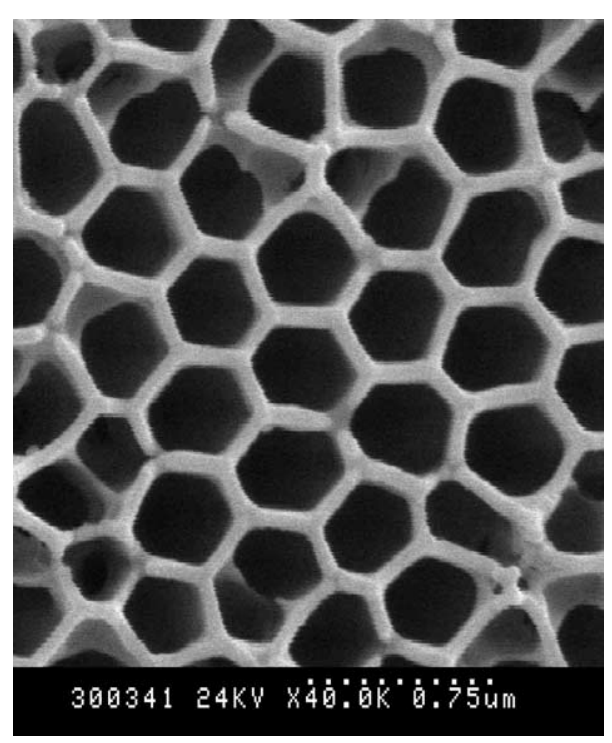

Fig. 1. SEM image of porous anodic alumina film (plane view) fabricated at constant current density of $5.5 \mathrm{~mA} / \mathrm{cm}^{2}$ in $1.2 \mathrm{M}$ $\mathrm{H}_{3} \mathrm{PO}_{4}$ electrolyte.

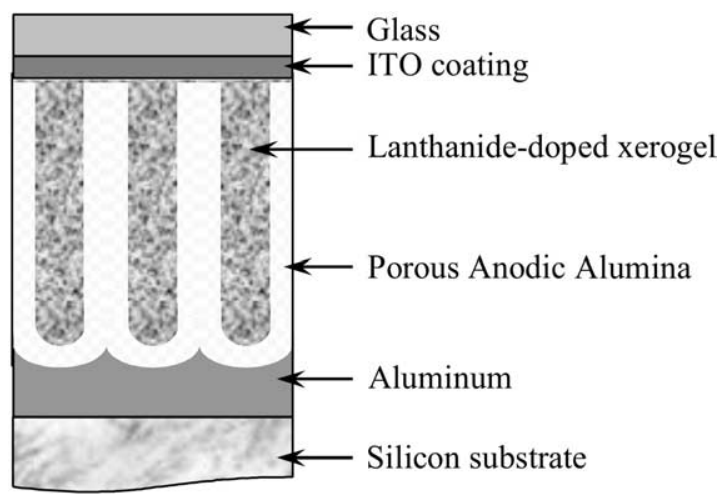

Fig. 2. Schematic view of EL cell comprising xerogel/porous anodic alumina structure, fabricated on silicon. The structure reveals visible $\mathrm{Eu}$ or $\mathrm{Tb}$ related luminescence when positive potential above 40 or $90 \mathrm{~V}$ is applied to the ITO electrode for $\mathrm{Eu}$ or $\mathrm{Tb}$ doped $\mathrm{In}_{2} \mathrm{O}_{3}$ and $\mathrm{SnO}_{2}$ xerogels, respectively.

\section{Results and discussion}

\subsection{53 $\mu \mathrm{m}$ Infrared emission}

Erbium-doped titania xerogel films, fabricated on PAA, reveal strong room-temperature PL at $1.53 \mu \mathrm{m}$, which is associated with the ${ }^{4} \mathrm{I}_{13 / 2} \rightarrow$
${ }^{4} \mathrm{I}_{15 / 2}$ transition of $\mathrm{Er}^{3+}$ in the titania xerogel (Fig. 3). Depending on the excitation wavelength, the erbium PL increases or decreases with the number of deposited xerogel layers. Particularly it increases for the $532 \mathrm{~nm}$ excitation wavelength (Fig. 3(a)) and decreases for the $300 \mathrm{~nm}$ wavelength. Erbium PL increases also with the increase of $\mathrm{Er}_{2} \mathrm{O}_{3}$ concentration in the titania xerogel from 30 to $60 \mathrm{wt} \%$ (Fig. 3(c)). The observed behaviour of the erbium PL intensity with the number of xerogel layers for these two excitation wavelengths can be understood by considering the earlier transmittance measurements of titania xerogel and porous anodic alumina [20]. Contrary to the $300 \mathrm{~nm}$ excitation wavelength, both the titania xerogel and the porous anodic alumina reveal a higher transparency for the $532 \mathrm{~nm}$ excitation wavelength, providing favourable conditions for light propagation at $532 \mathrm{~nm}$ and $1.53 \mu \mathrm{m}$. Thus, an increase in the titania xerogel content (amount of active luminescent centres) results in an increase of the erbium PL intensity for the $532 \mathrm{~nm}$ excitation wavelength. It may be probable to increase further the $1.53 \mu \mathrm{m}$ emission by increase of erbium concentration in xerogel and the number of xerogel layers. The samples do not reveal a strong concentration quenching of erbium photoluminescence unlike erbium-implanted semiconductors, and the transparency of titania at the excitation wavelength allows a further build up of the xerogel layers within the anodic alumina pores.

\subsection{Electroluminescent cell}

When a positive potential is applied to the ITO electrode for the structure of Fig. 2, the visible red (europium-doped xerogels) and green (terbiumdoped xerogels) emission appears at applied voltages above 40 and $90 \mathrm{~V}$ for $\mathrm{In}_{2} \mathrm{O}_{3}$ and $\mathrm{SnO}_{2}$ xerogels, respectively. The observed light emission from this structure is associated with the dominant optical transitions ${ }^{5} \mathrm{D}_{0} \rightarrow{ }^{7} \mathrm{~F}_{2}$ of $\mathrm{Eu}^{3+}$ at $617 \mathrm{~nm}$ and ${ }^{5} \mathrm{D}_{4} \rightarrow{ }^{7} \mathrm{~F}_{5}$ of $\mathrm{Tb}^{3+}$ at $545 \mathrm{~nm}$ in $\mathrm{In}_{2} \mathrm{O}_{3}$ and $\mathrm{SnO}_{2}$ xerogels. Both of the fabricated structures, with PAA thicknesses of 5 and $15 \mu \mathrm{m}$, exhibited visually similar intensities of emission.

The voltage current characteristics (VCC) of the EL structures are presented in Fig. 4. $\mathrm{In}_{2} \mathrm{O}_{3}$ 

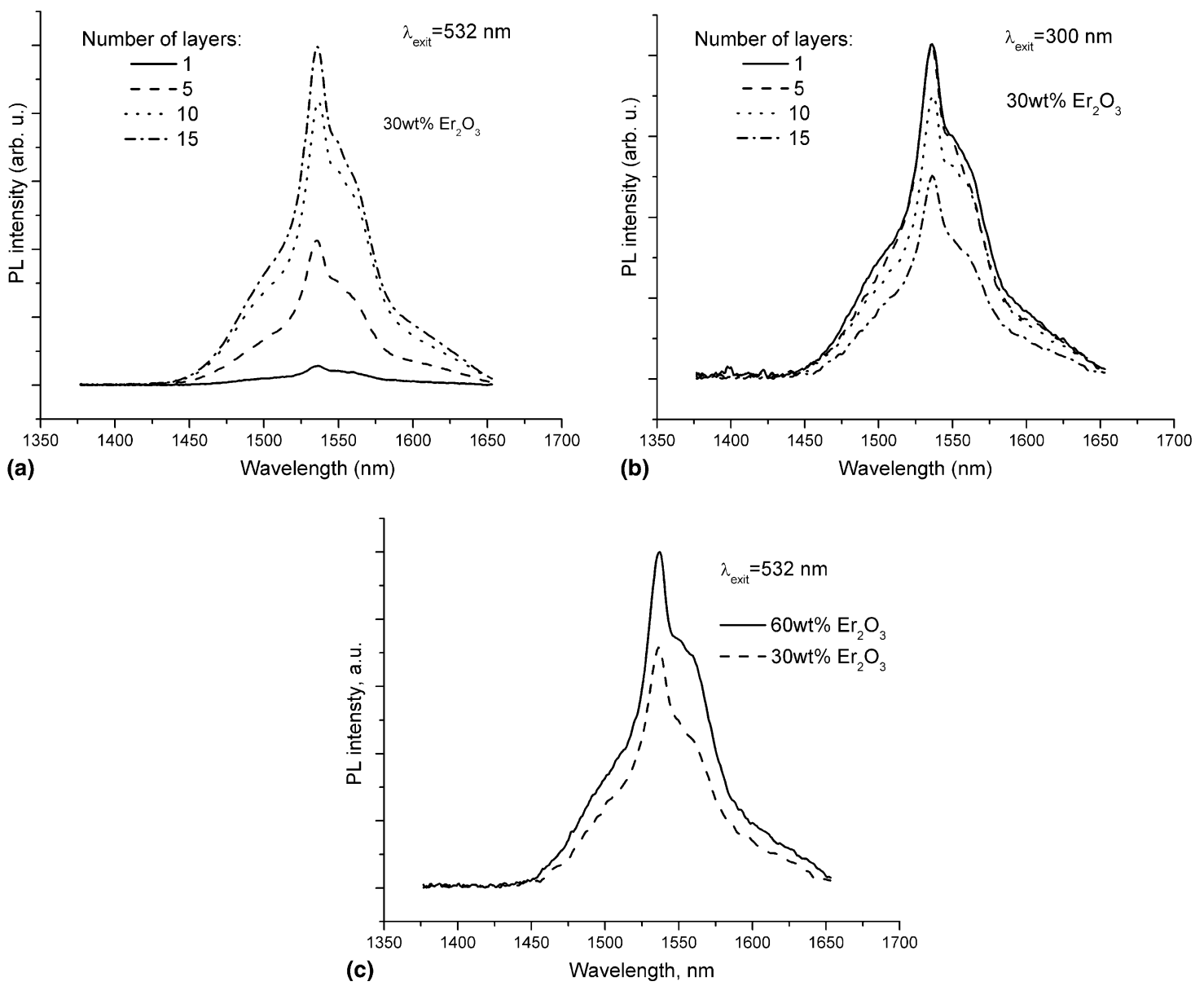

Fig. 3. PL spectra around $1.53 \mu \mathrm{m}$ from erbium doped titania xerogels layers ( 30 and $60 \mathrm{wt} \% \mathrm{Er}_{2} \mathrm{O}_{3}$ ) deposited by spinning from 1 to 15 times onto porous anodic alumina followed by annealing at $900{ }^{\circ} \mathrm{C}$ for $20 \mathrm{~min}$.

xerogel based structures operate at lower voltages than that of $\mathrm{SnO}_{2}$. From the shape of the VCC, it is concluded that the EL mechanism involves a double injection (holes from the ITO layer and electrons from the bottom electrode) and a recombination of the carriers in the phosphor with a transfer of the energy to the lanthanide ions resulting in a photon emission.

Further lowering of the electrical resistance of the xerogel/porous anodic alumina structure can be achieved by: (i) ensuring more reliable electrical contact between the conductive xerogel and the upper conductive electrode and (ii) improving the conductivity of the xerogel material, doped with the lanthanide ions.
Ensuring electrical contact may be achieved by use of an additional conductive sublayer, this conductive sublayer could comprise ITO nanoparticles [19]. Typically, an $0.5 \mu \mathrm{m}$ thick ITO-film, with a sheet resistance of about $500 \Omega / \square$ can be obtained by spinning a suspension of ITO nanoparticles followed by annealing at $550{ }^{\circ} \mathrm{C}$.

The ability of the dispersed nanoparticles to penetrate through the channels of the anodic alumina pores was investigated with SEM, and the images reveal their penetration into the channels of the anodic alumina after simple spin deposition from dispersion (Fig. 5). The degree of pore filling increases by sequential deposition of spin-on layers from one to five. Further, the diffusion of the lan- 


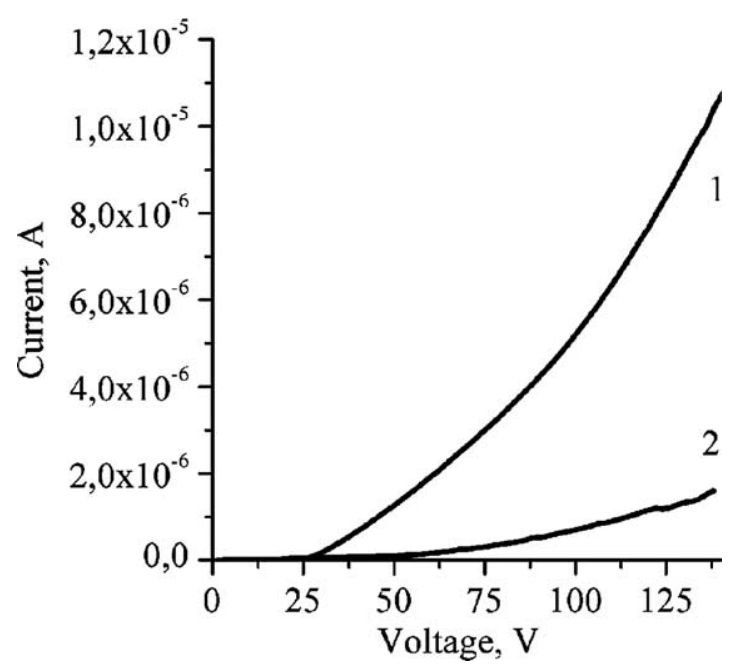

Fig. 4. Voltage current characteristics of EL structure fabri cated on PAA of $15 \mu$ thick with Eu doped xerogel films: xerogel $\mathrm{Eu}_{2} \mathrm{O}_{3} \quad \mathrm{In}_{2} \mathrm{O}_{3}$ (curve 1), $\mathrm{Eu}_{2} \mathrm{O}_{3} \quad \mathrm{SnO}_{2}$ (curve 2). Sample dimensions are $5 \times 5 \mathrm{~mm}^{2}$.

thanide ions into the ITO-particles seems unfavourable. Examination of the structure fused silica/ITOfilm/europium-or terbium-doped titania xerogel, subjected to a conventional furnace annealing at $1000{ }^{\circ} \mathrm{C}$ for $12 \mathrm{~h}$ does not reveal diffusion of lantha- nide ions into ITO nanoparticles. Furthermore, room-temperature measurements of the sheet resistivity, photoluminescence and photoluminescence excitation spectroscopy (PLE) do not confirm lanthanide diffusion as well. These structures exhibit PL and PLE spectra typical of terbium and europium in titania xerogels reported earlier $[4,5]$.

In order to improve the conductivity of the xerogel material, several coatable solutions, with the $\mathrm{Sn} / \mathrm{In}$ ratio in the ITO-xerogel ranging from 4 to $14 \mathrm{~mol} \%$, have been fabricated. The sheet resistance measurements of the corresponding ITO-xerogel spin-on films are presented in Table 1.

Table 1

Sheet resistance $(\mathrm{k} \Omega / \square)$ of ITO xerogel films fabricated on $\mathrm{SiO}_{2} / \mathrm{Si}$ structure depending on the annealing temperature and the $\mathrm{Sn} / \mathrm{In}$ ratio

\begin{tabular}{lrrrrrr}
\hline $\begin{array}{l}\text { Sn/In ratio } \\
(\mathrm{mol} \%)\end{array}$ & \multicolumn{6}{l}{ Annealing temperature $\left({ }^{\circ} \mathrm{C}\right)$} \\
\cline { 2 - 7 } & 500 & 600 & \multicolumn{1}{c}{700} & 800 & 900 & 1000 \\
\hline 4 & $>100$ & $>100$ & $>100$ & 90 & 80 & $>100$ \\
8 & 45 & 35 & 60 & 97 & 75 & 25 \\
10 & 30 & 25 & 30 & 45 & 80 & $>100$ \\
14 & 83 & $>100$ & $>100$ & $>100$ & $>100$ & $>100$ \\
\hline
\end{tabular}

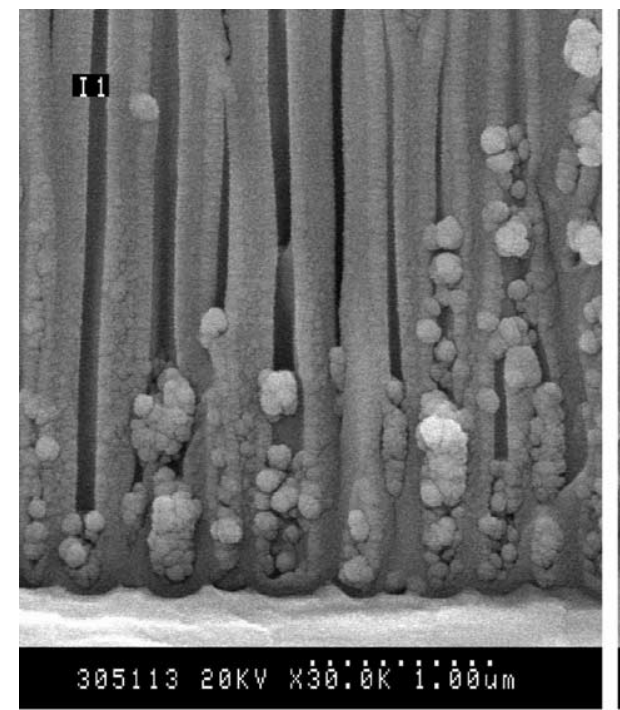

(a)

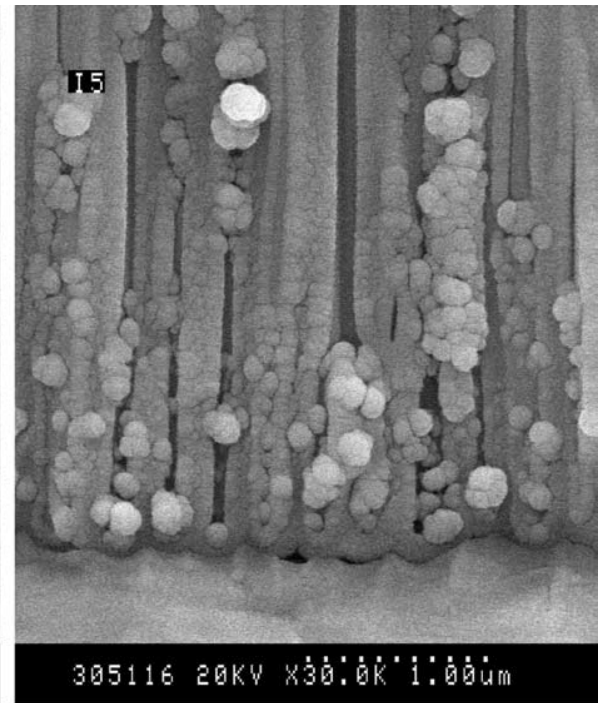

(b)

Fig. 5. SEM images of porous anodic alumina after one (a) and five (b) depositions of ITO nanoparticles fabricated by spinning from suspension. 
The most conductive ITO-xerogel films were found with $\mathrm{Sn} / \mathrm{In}$ ratio of 8 and $10 \mathrm{~mol} \%$ subjected to thermal treatment at a temperature ranging from 500 to $700{ }^{\circ} \mathrm{C}$. However, additional doping of these films with $30 \mathrm{wt} \% \mathrm{Eu}_{2} \mathrm{O}_{3}$ results in a marked (two orders of magnitude) decrease of their conductivity.

Probably, other transparent conductive oxides such as $\mathrm{ZnO}: \mathrm{Al}$ (AZO) [21], $\mathrm{SnO}_{2}: \mathrm{Sb}$ (ATO) [22], along with their moderate doping with lanthanide ions, could provide layers of lower resistivity. Their sol gel synthesis in porous anodic alumina may also further improve the electrical characteristics of the electroluminescent cell comprising the xerogel/porous anodic alumina structure.

\section{Conclusions}

Structures comprising lanthanide-doped (erbium, terbium and europium) xerogel/porous anodic alumina have been synthesized. Photoluminescence at $1.53 \mu \mathrm{m}$, by excitation at $532 \mathrm{~nm}$ of the erbium-doped titania xerogel increases with the erbium concentration and the number of xerogel layers. This excitation wavelength is optimum for the transparency of both the titania xerogel and porous anodic alumina.

Visible green and red electroluminescence, observed for terbium- and europium-doped $\mathrm{In}_{2} \mathrm{O}_{3}$ and $\mathrm{SnO}_{2}$ xerogels embedded in porous anodic alumina, is reported. Advanced development of xerogel/porous anodic alumina structure is thought to arise from the observed ability of ITO nanoparticles to penetrate the anodic alumina pores. This can provide more reliable electrical contact between the conductive electrode and the conductive xerogels doped with the lanthanide ions. This effect and the influence of lanthanide ions on the conductivity of other conductive xerogel materials like $\mathrm{ZnO}: \mathrm{Al}$ and $\mathrm{SnO}_{2}: \mathrm{Sb}$ and their possible synthesis in two-dimensional periodical porous anodic alumina cells will be addressed in subsequent papers.

\section{Acknowledgements}

This work was supported by INTAS (project 03-51-6486) and the International Science Techno- logical Centre (project B-276.2). N.V. Gaponenko is also grateful to DAAD for supporting a research visit of the Leibniz Institut fuer Neue Materialien, Department of Coating Technology, Saarbruecken. Stimulating discussion with Prof. G.E. Thompson (The University of Manchester) and technical assistance of Dr. E.A. Stepanova (Belarussian State University of Informatics and Radioelectronics) in sol gel synthesis are gratefully acknowledged.

\section{References}

[1] G.E. Thompson, R.C. Furneaux, G.C. Wood, J.A. Rich ardson, J.S. Goode, Nature 272 (1978) 433.

[2] V.P. Parkhutik, V.I. Shershulsky, J. Phys. D 25 (1992) 1258.

[3] N.V. Gaponenko, V.M. Parkun, O.S. Katernoga, V.E. Borisenko, A.V. Mudryi, E.A. Stepanova, A.I. Ratko, M. Cavanagh, B. OḰelly, J.F. McGilp, Thin Solid Films 297 (1997) 202.

[4] N.V. Gaponenko, J.A. Davidson, B. Hamilton, P. Skel don, G.E. Thompson, X. Zhou, J.C. Pivin, Appl. Phys. Lett. 76 (2000) 1006.

[5] N.V. Gaponenko, I.S. Molchan, G.E. Thompson, P. Skeldon, A. Pakes, R. Kudrawiec, L. Bryja, J. Misiewicz, Sensor. Actuator. A 99 (2002) 71.

[6] X. Zhoy, M. Pfeffer, J. Blochwitz, A. Werner, A. Nollau, T. Fritz, K. Leo, Appl. Phys. Lett. 78 (2001) 412.

[7] E.A. Lebedev, M.Ja. Goikhman, K.D. Tsendin, I.V. Podeshvo, E.I. Terukov, V.V. Kudrjavtsev, Semiconduc tors 38 (2004) 1078.

[8] N.A. Poklonski, E.F. Kislyakov, D.I. Sagadak, A.I. Siaglo, G.G. Fedoruk, Tech. Phys. Lett. 27 (2001) 180.

[9] H.A. Lopez, P.M. Fauchet, Phys. Status Solidi A 182 (2000) 413.

[10] A. Moadhen, H. Elhouichet, S. Romdhane, M. Oueslati, J.A. Roger, H. Bouchriha, Semicond. Sci. Tech. 18 (2003) 703.

[11] H. Elhouichet, A. Moadhen, M. Ferid, M. Oueslati, B. Canut, J.A. Roger, Phys. Status Solidi A 197 (2003) 350.

[12] N.V. Gaponenko, I.S. Molchan, A.A. Lutich, S.V. Gap onenko, Solid State Phenom. 9798 (2004) 251.

[13] A.A. Lutich, S.V. Gaponenko, N.V. Gaponenko, I.S. Molchan, V.A. Sokol, V. Parkhutik, Nano Lett. 4 (2004) 1755.

[14] N.V. Gaponenko, I.S. Molchan, O.V. Sergeev, G.E. Thompson, A. Pakes, P. Skeldon, R. Kudrawiec, L. Bryja, J. Misiewicz, J.C. Pivin, B. Hamilton, E.A. Stepanova, J. Electrochem. Soc. 149 (2002) H49.

[15] I.S. Molchan, N.V. Gaponenko, R. Kudrawiec, J. Mis iewicz, G.E. Thompson, Mat. Sci. Eng. B 105 (2003) 36.

[16] N.V. Gaponenko, O.V. Sergeev, E.A. Stepanova, V.M. Parkun, A.V. Mudryi, H. Gnaser, J. Misiewicz, R. 
Heiderhoff, L.J. Balk, G.E. Thompson, J. Electrochem. Soc. 148 (2001) H13.

[17] M. Ishii, S. Komuro, T. Morikawa, J. Appl. Phys. 94 (2003) 3823.

[18] S. Jeon, P.V. Braun, Chem. Mater. 15 (2003) 1256.

[19] N. Al Dahoudi, H. Bisht, C. Goebbert, T. Krajewski, M.A. Aegerter, Thin Solid Films 392 (2001) 299.
[20] I.S. Molchan, N.V. Gaponenko, R. Kudrawiec, J. Mis iewicz, G.E. Thompson, P. Skeldon, J. Electrochem. Soc. 151 (2004) H16.

[21] T. Schuler, M.A. Aegerter, Thin Solid Films 351 (1999) 125.

[22] M.A. Aegerter, A. Reich, D. Ganz, G. Gasparro, J. Puetz, T. Krajewski, J. Non Cryst. Solids. 218 (1997) 123. 